\title{
U.S. Department of Energy Global Change Fellowships, 1991-2006: Participant Follow-Up
}

\section{Technical Report}

September 2006

Prepared by:

Oak Ridge Institute for Science and Education

Prepared for:

U.S. Department of Energy

Office of Biological and Environmental Research

Climate Change Research Division 
The Oak Ridge Institute for Science and Education (ORISE) is a U.S. Department of Energy institute focusing on scientific initiatives to research health risks from occupational hazards, assess environmental cleanup, respond to radiation medical emergencies, support national security and emergency preparedness, and educate the next generation of scientists. ORISE is managed by Oak Ridge Associated Universities. 


\title{
U.S. Department of Energy Global Change Fellowships, 1991-2006: Participant Follow-Up
}

\author{
Technical Report
}

\author{
Prepared for: \\ U.S. Department of Energy \\ Office of Biological and Environmental Research \\ Climate Change Research Division \\ Prepared by: \\ Oak Ridge Institute for Science and Education
}

September 2006

This document was produced under contract number DE-AC05-06OR23100 between the U.S. Department of Energy and Oak Ridge Associated Universities.

All opinions expressed in this paper are the author's and do not necessarily reflect policies and views of the U.S. Department of Energy , Oak Ridge Institute for Science and Education, or Oak Ridge Associated Universities. 


\section{Table of Contents}

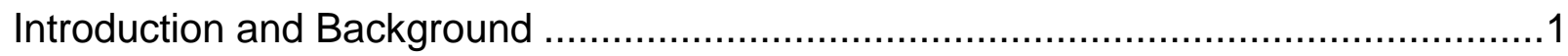

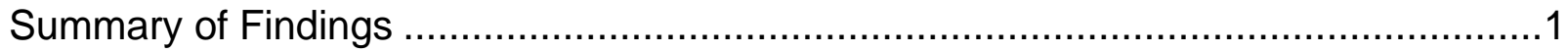

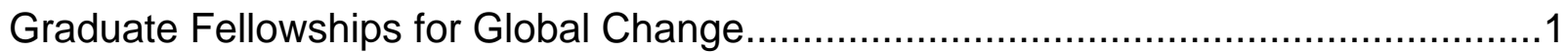

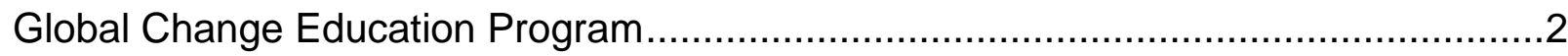

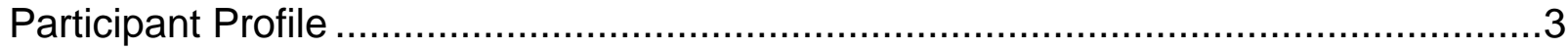

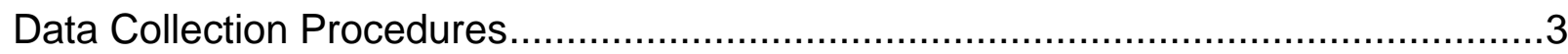

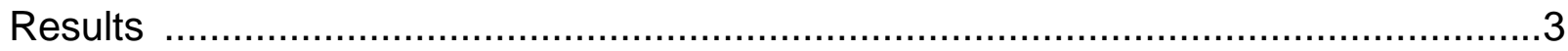

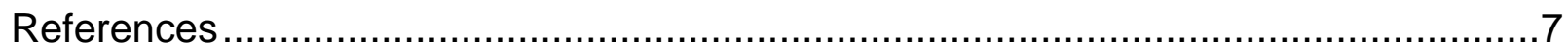

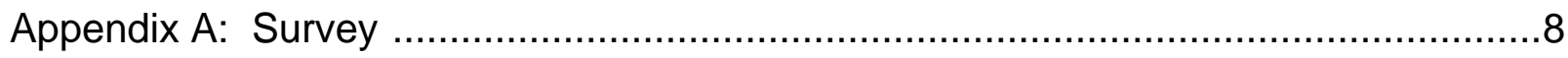

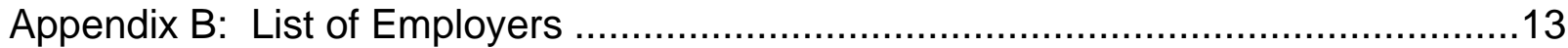

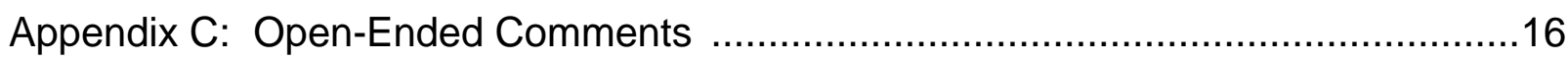




\section{Introduction and Background}

This report provides information on the impact of two U.S. Department of Energy (DOE) programs supporting graduate study related to global change. The information was obtained from former fellows in the two programs, and the report examines their subsequent careers and the benefits of program participation.

In 1991, the DOE Office of Health and Environmental Research (OHER) established the Graduate Fellowships for Global Change (GFGC) to promote training in support of DOE's global change research activities. Global change research encompasses a wide variety of study areas, including atmospheric sciences, ecology, global carbon cycles, climatology, and terrestrial processes.

In 1999, DOE's Office of Biological and Environmental Research (OBER), formerly OHER, replaced the GFGC program with the current Global Change Education Program (GCEP), which encompasses both undergraduate and graduate training in global change. Dr. Jeffrey S. Gaffney of the Argonne National Laboratory was named Chief Scientist for the program; Dr. Milton Constantin of the Oak Ridge Institute for Science and Education (ORISE), Program Manager of GFGC, continued in this capacity for GCEP. Oak Ridge Associated Universities (ORAU) manages ORISE for the U.S. Department of Energy.

\section{Summary of Findings}

Of the 92 former participants in the DOE Global Change Fellowship programs from 1991 to 2006, the follow-up study located 82 by e-mail or postal mail and received responses from 74, for a response rate of 90 percent.

- The majority of respondents remain involved in research that evolved from or is similar to their fellowship research.

- Almost two-thirds were employed by universities.

- $\quad$ About three-fourths of the respondents noted that their work during the past year had been supported by grants or contracts from U.S. Government agencies; of these, about one-fourth had funding from DOE.

- Comments by respondents were extremely complimentary of the Global Change Fellowships, especially the opportunities and networks it provided them and the financial support that enabled them to complete doctorates.

- Positive comments were also received about the management and administration of the programs.

\section{Graduate Fellowships for Global Change}

The U.S. Global Change Research Program resulted from a Presidential Initiative in the FY1990 budget. Developed by the Committee on Earth and Environmental Sciences of the Federal Coordinating Council for Science, Engineering and Technology, the program was ". . . driven by carefully established priorities that must be addressed to establish sound national and international policies related to global environmental issues, particularly global climate change."

The Graduate Fellowships for Global Change Program was patterned after other successful graduate fellowships sponsored by DOE and its predecessor organizations, the U.S. Atomic Energy Commission and the U.S. Energy Research and Development Agency. The model for these various fellowships included the following:

- designated participating universities

- graduate students selecting first- and second-choice universities from the list of participating universities at the time of application

- fellows participating in at least one practicum at a DOE facility

- fellows' dissertation and practicum research supportive of the DOE mission. 
Benefits to the graduate fellows included a monthly stipend, paid tuition and fees, and the reimbursement of travel expenses. The fellows participated in a summer practicum at a DOE research facility.

The GFGC program began during FY1991 with the first fellows in September of that year. Program objectives aimed to:

1. ensure an adequate supply of appropriately trained scientists and engineers to carry out the government's mission in global change research

2. make available national DOE R\&D and other federal government facilities for training in global change research

3. strengthen collaborative ties between the national academic community, DOE facilities, and other federal agencies and laboratories in all aspects of global change research through graduate student training and research

4. increase the visibility of careers in global change research and encourage students to pursue such careers,

5. enhance the academic community's commitment to education, training, and research in disciplines supportive of global change research

6. encourage graduating fellows to accept employment with DOE, DOE contractors, or other federal agencies.

Academically talented students were recruited and supported in their graduate studies and research in areas of climate and hydrologic systems, biogeochemical dynamics, ecological systems and dynamics, earth system history, human interactions, solid earth processes, and solar processes as applicable to global change. The program's goals were to provide formal education for the next generation of scientists involved with all aspects of global change.

\section{Global Change Education Program}

The current Global Change Education Program (GCEP) was established in 1999 to promote both undergraduate and graduate training in support of DOE's global change research activities. Components of the current GCEP include the Summer Undergraduate Research Experience (SURE) and the Graduate Research Environmental Fellowships (GREF). The focus for this follow-up study was on the graduate component, which aims to further improve the quality of emerging scientists in disciplines related to global change research by supporting graduate students in three-year fellowships.

Funded by the Office of Biological and Environmental Research, the GREF program began in September 1999 to support graduate students engaged in collaborative global change research at universities and national laboratories. All qualified students are encouraged to apply, but minority and female students are particularly encouraged. The fellowship's three-year appointments are renewable annually, and include an annual stipend of $\$ 18,000$ plus tuition and fees and a supplement for travel and materials.

GREF applicants must have completed their first year in graduate school, unless they have participated previously in SURE. Applicants must submit a five-page description of proposed research, letters of recommendation from the two mentors and an outside individual, and undergraduate and graduate transcripts. The annual fellowship renewal depends on evidence of the fellow's satisfactory academic and research direction and progress.

An important aspect of the GREF project is the encouragement of interdisciplinary work among colleges, universities, and national laboratories involved in global change research efforts. Proposed doctoral research projects that bridge the gaps between the various GCEP programmatic research efforts are particularly welcome. GREF fellows have two mentors: a university faculty advisor and a national laboratory researcher who collaboratively guide the research activities. 


\section{Participant Profile}

There were a total of 64 participants in the Graduate Fellowships for Global Change (GFGC) for the years 19911999. Of these, 43 were male and 21 were female.

For the current Global Change GREF program, which began in 1999, there have been 28 participants who had completed their fellowships at the time of the follow-up survey. Of these, 6 were male and 22 female.

\section{Data Collection Procedures}

In order to determine impacts of the Global Change Fellowships (both GFGC and GREF) on former participants, a follow-up study was conducted in July 2006. Since the study included former participants who completed their fellowships from 1994 through July 2006, both short-term and long-term perspectives were obtained. The former participants from both programs were e-mailed the following request:

"We are contacting you to ask how participation in a Department of Energy Global Change Fellowship has affected your career to date. In summarizing the data collected, we hope to determine the value of the program and maintain support for this program and other similar fellowship programs."

The survey link was included in the e-mail; upon completion, the responses were submitted electronically. The survey questions are included in Appendix A of this report. The questions sought to collect information about former participants' current employment, research activities, and funding. The other important aspect of the follow-up survey is to update contact information for former fellows and track down those for whom information has become outdated.

For those not responding initially, a second e-mail was sent, and the ORISE program manager attempted to contact the nonrespondents or their former mentors by phone. The personal contact resulted in obtaining updated addresses and responses from many of these former participants.

A third attempt was made to contact by postal mail all those who had not responded by e-mail. For those for whom the e-mail address was unknown, the letter was mailed to their last known mailing address and/or to their last known university address.

Of the 92 former participants, e-mail addresses were unknown for 6 from the earlier program. In addition, e-mails were returned as undeliverable for 4 former participants, all of whom were also from the earlier program. Thus, we assume that we reached 82 of the former participants, after subtracting the number for whom the address was unknown or undeliverable.

Responses were received from a total of 74 former participants, for an overall response rate of 90 percent (based on the 82 known addresses). There were 46 responses from the 1991-1999 Global Change Education Fellows and 28 from the 1999-2006 GREF Fellows. It is not surprising that the response rate was much greater for the more recent group of fellows (100 percent versus 85 percent) since their contact information was relatively current.

\section{Results}

\section{Current Employment/Postdoctorate Information}

Of the respondents to the follow-up survey, almost three-fourths indicated they are currently employed (other than as a postdoctoral fellow), with most of the remainder indicating they are currently postdoctoral fellows. All but one of those indicating they hold postdocs were among the more recent 1999-2006 fellows, which is not surprising since they are younger and not as far along in their careers. Of the respondents providing information, only 4 were unemployed: one of whom was a nursing student, one soon to be employed, one traveling, and one staying home with her child. 


\section{Current Employment Status of Respondents}

\begin{tabular}{|l|r|r|}
\hline & Number & Percent \\
\hline Unemployed & 4 & $5.4 \%$ \\
\hline Postdoctoral Fellow & 16 & $21.6 \%$ \\
\hline Employed, Not a Postdoctoral Fellow & 54 & $73.0 \%$ \\
\hline \multicolumn{1}{|r|}{ TOTAL } & 74 & $100.0 \%$ \\
\hline
\end{tabular}

Employers include large corporations, well-known nonprofits, national research laboratories, government agencies, and universities. The largest percentage by far was for universities, with almost two-thirds of the responses. The university with the largest number of former participants was University of Washington, with 6 respondents reporting it as their employer.

\section{Current Employer of Respondents}

\begin{tabular}{|c|c|c|}
\hline & Number & Percent \\
\hline DOE or a DOE laboratory & 3 & $4.2 \%$ \\
\hline University & 46 & $64.8 \%$ \\
\hline \multicolumn{3}{|l|}{ Other: } \\
\hline Government & 7 & $9.9 \%$ \\
\hline Private industry & 9 & $12.7 \%$ \\
\hline Nonprofit & 4 & $5.6 \%$ \\
\hline Self-employed & 1 & $1.4 \%$ \\
\hline Not specified & 1 & $1.4 \%$ \\
\hline TOTAL* & 71 & $100.0 \%$ \\
\hline
\end{tabular}

* One respondent reported two employers.

In addition to the universities, prestigious employers included three national labs, three federal agencies (EPA, USGS, and USDA), large corporations (for example, GM and Target), large nonprofits (National Audubon Society and The Nature Conservancy), and educational research institutes (for example, Woods Hole Oceanographic Institution). Two former participants reported affiliations with the U.S. Senate (congressional science fellow; energy and environmental advisor for U.S. Senator), and one is a nonpartisan researcher for the Minnesota Senate.

See Appendix B for a complete list of the current employers as reported by the respondents.

\section{Research/Professional Activities Since Fellowship}

When asked about their current research activities as related to the global change graduate student fellowship research, the largest proportion (almost 60 percent) indicated that they are involved in research that "evolved" from their graduate studies research. An additional 13.5 percent said they are involved in the "same or very similar" research.

Of the 10 respondents who indicated they are currently NOT involved in research, most are unemployed or work for large corporations or nonprofits. 


\section{Current Research Activities Compared with Fellowship Research}

\begin{tabular}{|c|c|c|}
\hline & Number & Percent \\
\hline Current research the same or very similar & 10 & $13.5 \%$ \\
\hline Current research evolved from graduate studies research & 44 & $59.5 \%$ \\
\hline Current research has little or no relationship to fellowship research & 10 & $13.5 \%$ \\
\hline Not involved in research & 10 & $13.5 \%$ \\
\hline TOTAL & 74 & $100.0 \%$ \\
\hline
\end{tabular}

In comparing the participants from the Graduate Fellowships for Global Change (1991-1999) with the more recent GREF participants (1999-2006), the percentages indicating they are involved in research that "evolved" from their fellowship are very similar, 59 percent versus 61 percent respectively. However, because of the shorter time frame, it is not surprising that a larger proportion of the more recent fellows indicated they are involved in the "same or very similar" research, 21 percent versus 9 percent for the 1991-1999 fellows responding. A chi square test found no significant differences between the two groups, however, in terms of their current research activities.

Nine respondents (12 percent) reported they had been named principal investigator ( $\mathrm{PI}$ ) or co-PI on research proposals submitted to the Department of Energy or DOE laboratories. The number of proposals per individual averaged 2.7 and ranged from 1 to 8 ; of these, the number of proposals funded averaged 1.6 with a range of 0 to 4.

Almost three-fourths of the respondents noted that their work during the past 12 months had been supported by contracts or grants from U.S. Government agencies. Almost half of these with Government funding indicated it came from the National Science Foundation, followed by almost one-third with Department of Commerce funding, and almost one-fourth each with Department of Energy and NASA funding.

\section{Federal Agencies or Departments Supporting Work of Respondents}

\begin{tabular}{|l|r|r|}
\hline & Number & Percent \\
\hline Agriculture Department (USDA) & 9 & $17.0 \%$ \\
\hline Commerce Department, including NOAA (DOC) & 16 & $30.2 \%$ \\
\hline Defense Department (DOD) & 7 & $13.2 \%$ \\
\hline Department of Education (includes NCES, OERI, FIPSE, FIRST) & 1 & $1.9 \%$ \\
\hline Department of Energy (DOE) or DOE laboratories & 12 & $22.6 \%$ \\
\hline Environmental Protection Agency (EPA) & 6 & $11.3 \%$ \\
\hline Interior Department & 3 & $7.5 \%$ \\
\hline National Aeronautics and Space Administration (NASA) & 12 & $22.6 \%$ \\
\hline National Institutes of Health (NIH) & 2 & $3.8 \%$ \\
\hline National Science Foundation (NSF) & 25 & $47.2 \%$ \\
\hline \multicolumn{2}{|c|}{ Number reporting federal support = 53 } & \\
\hline
\end{tabular}

Note: Respondents were asked to check all federal agencies that were applicable, thus percentages do not add to $100 \%$.

\section{Open-Ended Comments Related to Career and the Fellowship Program}

Almost three-fourths of the respondents took time to share personal comments related to their careers and the fellowship program. The comments were highly positive, both about the fellowship and the opportunities it affords, and also of the administrators of the program. See Appendix $\mathrm{C}$ for all comments provided by respondents.

The majority of respondents noted that the fellowship was "extremely beneficial" for their careers. Many commented on their appreciation for the financial support, which enabled them to complete doctorates that they 
otherwise might not have been able to. Frequent comments noted the development of professional networks as a result of the fellowship.

One noted, "The GCEP program was extremely important in my development as a researcher on many levels. It gave me many opportunities to present my research and develop public speaking abilities, it exposed me to a wide range of research that I would not have otherwise known about, and it provided a unique opportunity to interact with DOE scientists and officials at the summer meetings."

Additionally, they noted benefits for a variety of job sectors, such as, "Even with my job in private industry, I am able to support climate change research." Another noted, "I am excited to use my scientific background and research experience to affect positive change in government and public policy towards improved air quality." One respondent was "writing legislation on climate change and helping to craft a national energy policy."

Many respondents noted publications resulting from their fellowship research. Respondents also credited the fellowship for help in obtaining their current employment. For those employed by universities, many felt the fellowship had aided in their attaining tenure.

In addition to the career and academic benefits, several noted their appreciation for the "personal side of GCEP": "The program directors and managers have been very supportive and encouraging. My friends who have other graduate fellowships envy the personal contact that the GCEP students have with each other and those running the program." Another concluded, "I plan . . . to perhaps someday host a GCEP fellow."

Another stated, "In sum, I found the DOE program to be excellent, well administered, and the insistence on service at a national laboratory is well-conceived. It exposed me to a professional environment, provided me with many contacts (which I used many times), and gave me a sense of 'giving back' to the government." 


\section{References}

Oak Ridge Institute for Science and Education, Global Change Education Program (GCEP), 2003 Annual Report. GCEP Web site, http://www.atmos.anl.gov/GCEP/Information/mission.html 
Appendix A

Survey 


\section{Dear Former Fellow:}

As a past recipient of a Department of Energy Global Change Fellowship, your feedback is very important to us to enhance the program opportunities for future students. We are interested in obtaining information about your current employment and research activities and in learning how the fellowship was of benefit to you. This information will be used to determine the impacts of the program in which you participated. Thank you for contributing to this important endeavor.

Questions? Contact us by e-mail: gcep.followup@orau.org

Current Contact Information

Last Name:*

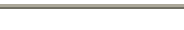

First Name:*

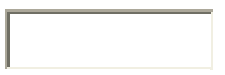

Middle Name or I nitial:

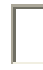

Street Address:

Address Line 1

Address Line 2

City

State

Zip

Phone Number:

(xxx) xxx-xxxx

Home

Work

Cell

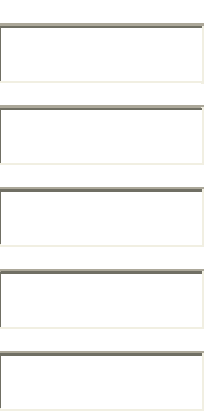


E-Mail Address:*

Home E-mail

Work E-mail

Current Employment/Postdoctorate Information

I am currently:

(Check one response.)

C Unemployed

C Postdoctoral fellow

E Employed, not a postdoctoral fellow

C Graduate student

O Other, please specify

My current employment/postdoctorate is with:

(Please give the name of the organization.)

$\overline{ }$

My current employer/postdoctorate is:

(Check one response.)

C DOE or a DOE laboratory

C Subcontractor for DOE or a DOE laboratory

C University

C Other

Research/Professional Activities Since Fellowship

During the last 12 months, was any of your work supported by CONTRACTS OR GRANTS from the U.S. Government?

$\boldsymbol{C}$ Yes
$\boldsymbol{C}$ No ( If no, skip the next question)

If YES, which federal agencies or departments were supporting your work? (Check all that apply.) 


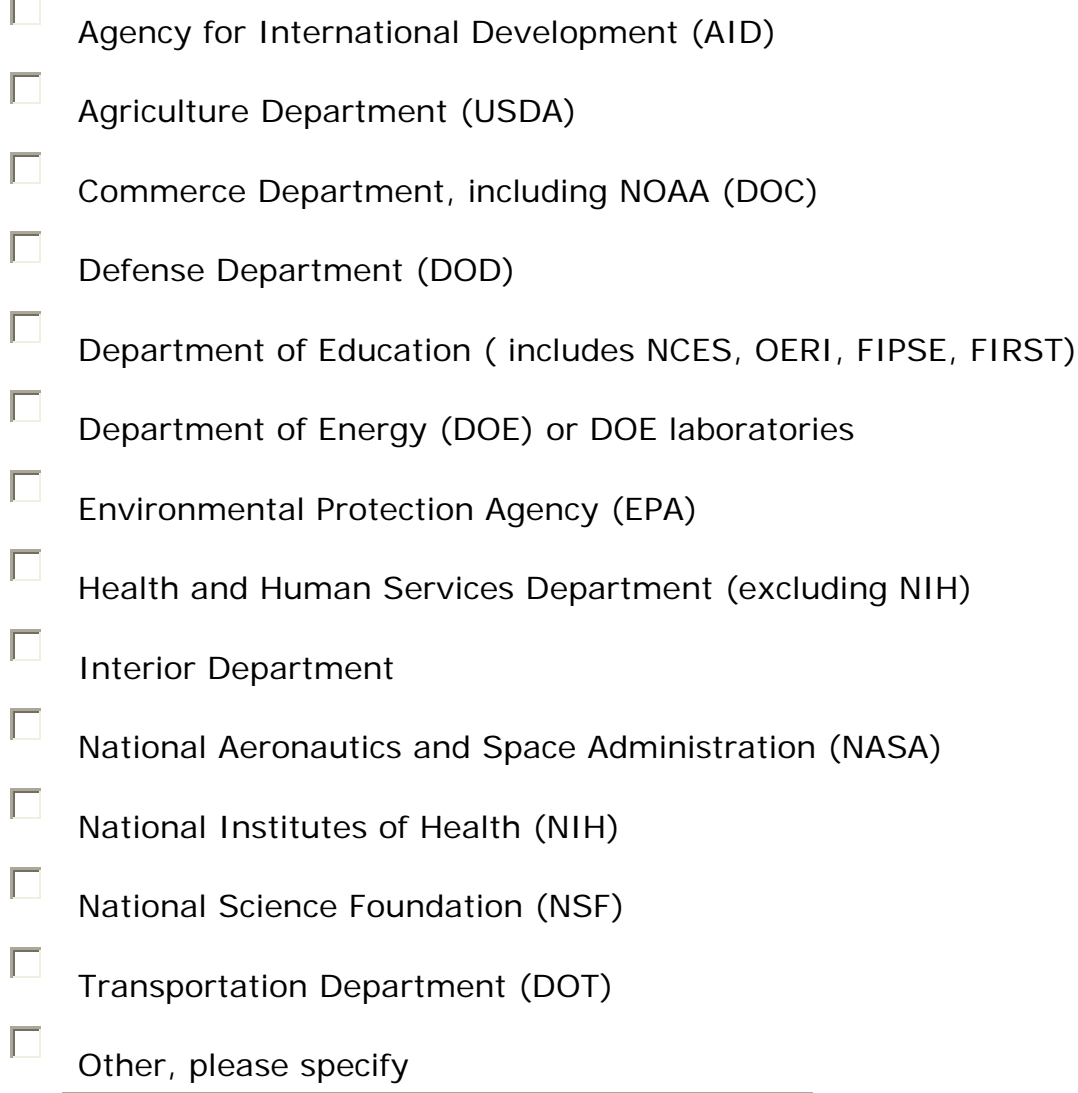

Indicate the extent to which your current research activities are related to your graduate student fellowship research. (Check one response.)

C Currently, I am involved in the same or very similar research.

C Currently, I am involved in research that evolved from my graduate studies research.

C There is little or no relationship between my current research and my fellowship research.

C I am not involved in research.

Have you been a principal investigator $(\mathrm{PI})$ or co-PI on research proposals submitted to the Department of Energy or DOE laboratories?
C Yes
C No

If yes,

how many proposals?

\# of proposals funded to date? 
Please provide any comments related to your career and the fellowship program that you would like to share with us.

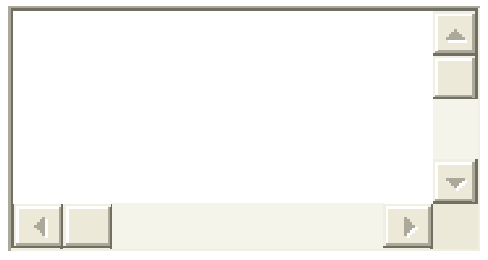




\section{Appendix B}

\section{List of Employers}




\section{Responses to survey question "my current employment/postdoctorate is with:"}

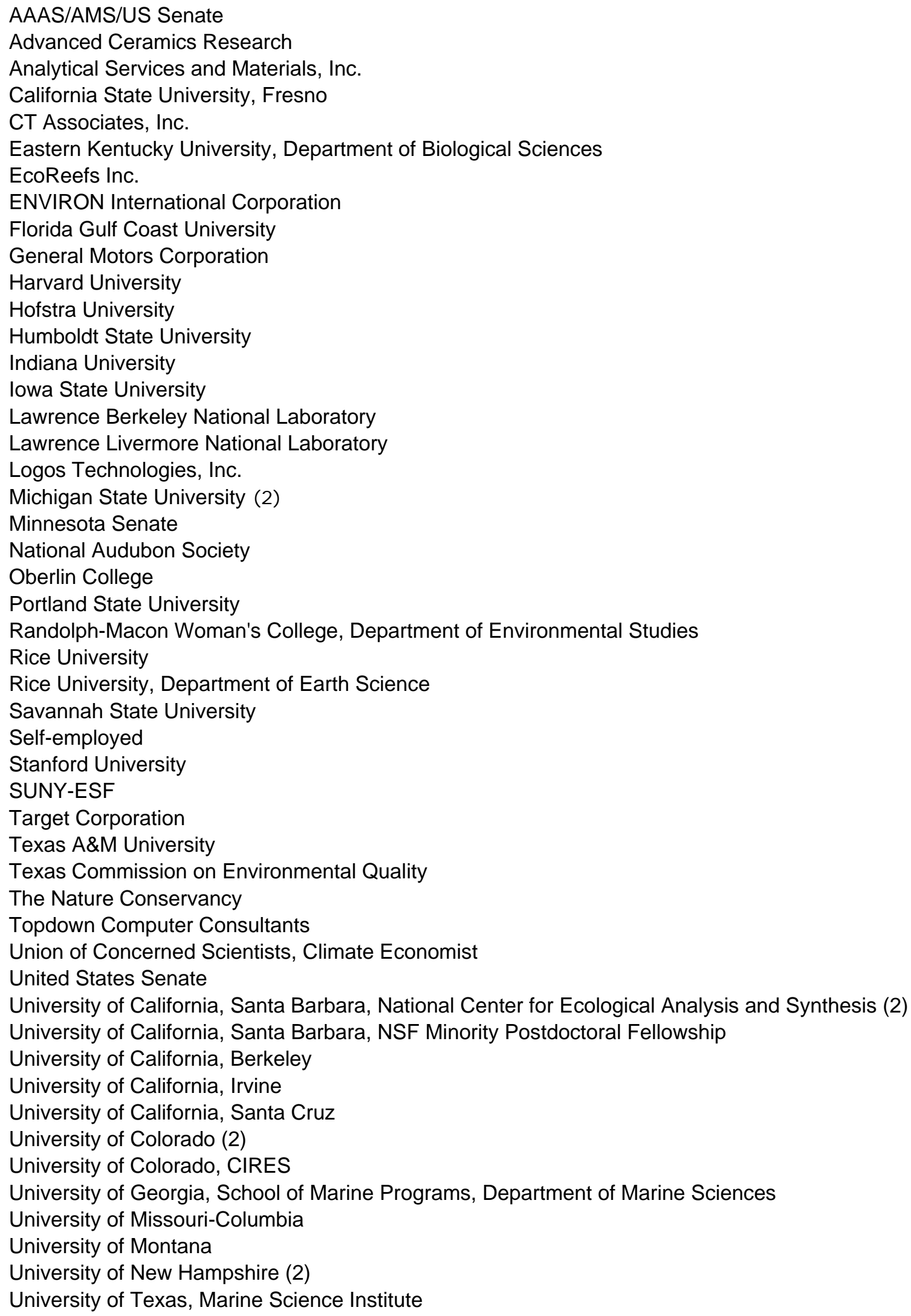


University of Washington (3)

University of Washington, Climate Impacts Group

University of Washington, Department of Atmospheric Sciences, Program on Climate Change University of Washington, Friday Harbor Laboratories

USDA, Agricultural Research Service

U.S. Environmental Protection Agency

U.S. Geological Survey

U.S. Naval Academy

UT-Battelle

Valparaiso University

Vegan Outreach

Washington State University, Vancouver

Wesleyan University

Woodland Park Zoo

Woods Hole Oceanographic Institution (2) 
Appendix C

Open-Ended Comments 


\section{Responses to open-ended survey question: "Please provide any comments related to your career and the fellowship program that you would like to share with us." $N=54$}

1. The fellowship was instrumental in supporting my graduate research and broadening my professional network.

2. The fellowship program was instrumental in ensuring that I would continue to work in climate change projects. Even with my job in private industry, I am able to support climate change research.

3. The best thing about the fellowship was the 3 months spent at a DOE lab that helped me make some contacts that got me a post-doc after graduation and got me to Colorado where I still live today. But ... it was difficult to leave my experimental research for 3 months to go work on a completely different project 2000 miles away.

4. This fellowship was very important to my graduate education, and thus career. Not only did it support me financially (and allow my adviser to fund other students), it gave me confidence. This confidence came from the recognition by others that the work I was doing was valuable and of a caliber worthy of support by a federal agency. I went on from the DOE Global Change fellowship, which supported my MS work, to be funded by a NASA Global Change fellowship during my doctoral work. I believe that the recognition I received from the DOE program helped me to earn the NASA fellowship, which was also quite important in my career.

5. The DOE GCEP program was a great experience. It was professionally run, and the workshops and meetings added much to my graduate research experience. The contacts I made with the other fellows as well as with DOE and other scientists have been really valuable. I plan to continue my career in atmospheric chemistry and perhaps someday to host a GCEP fellow. Thank you!

6. I found the fellowship program to be extremely beneficial for my career development. I have recently published two papers in well-known journals based on the work I did during my fellowship. Currently, I am searching for faculty positions at major research universities where I will continue to study aspects of global climate change. The fellowship played a large part in cultivating my interest in this research topic. Because of my positive experience while working at Argonne National Lab during my fellowship program, I intend to develop additional collaborations with DOE and other government scientists during my career.

7. The GCEP program was extremely important in my development as a researcher on many levels. It gave me many opportunities to present my research and develop public speaking abilities, it exposed me to a wide range of research that I would not have otherwise known about, and it provided a unique opportunity to interact with DOE scientists and officials at the summer meetings. The network of students and researchers has also been of use in my advancement, as well as the excellent group of people who administer the program. Finally, the funding was critical in providing me with freedom to pursue my research interests, and the research I did while funded through the GCEP program has resulted in four publications, which have helped jumpstart my career.

8. I will be joining the University of California, Merced as an assistant professor as of Oct 1, 2006. I have reviewed proposals for DOE, but haven't applied for any as a PI yet - but soon! I have primarily been funded by the California Energy Commission.

9. The DOE-GCEP program was instrumental in the completion of my $\mathrm{PhD}$, and also an important part of my experiences as a graduate student. Through the DOE-GCEP program, I formed a support group comprised of many individuals who helped me in various ways to survive the trials of research and graduate school. I interacted with many GCEPers at national meetings (especially AGU), and learned a great deal about other topics related to global change. I am truly grateful for all the DOE-GCEP program contributed to enriching my experience as a graduate student. Though the financial support for DOE-GCEP, I was able to devote my time solely to my research, and because of this support, I completed my dissertation with three of my four research chapters published or in press in major research journals (Atmospheric Chemistry and Physics, and Journal of Geophysical Research-Atmospheres), which has allowed me to devote my post-graduate days to other activities besides publishing work from graduate school. Although I have chosen not to pursue the academic path, I am still fully involved in issues of air pollution and global change through my new role as an environmental scientist at the US EPA Region 9 Air Division Permits Office. I am excited to use my scientific background and research experience to affect positive change in government and public policy towards improved air quality. I want to thank Jeff Gaffney (my mentor), Milt Constantin, and Mary Kinney for their support throughout my years as a GREF fellow. I hope to keep in touch with DOE-GCEP folks (both fellows, and program administrators): please feel free to email 
or call me at the above contact info. Please also let me know if there is any way that I can contribute to the continuation/expansion of this great program!

10. The DOE GCF was extremely helpful to me in my career. Not only did it allow me to focus on my work, rather than funding, during graduate school, but I was hired by the group with whom I conducted my national laboratory research term (NASA GSFC). I initially conducted research closely related to my PhD work, then evolved into higher level research problems with broader focus. In sum, I found the DOE program to be excellent, well administered, and the insistence on service at a national laboratory is well-conceived. It exposed me to a professional environment, provided me with many contacts (which I used many times), and gave me a sense of 'giving back' to the government.

11. I was a DOE Global Change Fellow from 1991 to 1996 focusing on past climate change. The beauty of the fellowship for me was twofold: it enabled me to pursue independent research that interested me; it provided opportunities to pursue new research (in my case, gas hydrates). Ten years later, I have been fairly successful by most measures (i.e., I am a tenured professor at Rice University, the chief editor of the AGU journal Paleoceanography, the top journal for research on past climates, and have been invited to give about 50 international talks on past climates and/or gas hydrates). Some significant portion of this success stems from the opportunities allowed through my DOE fellowship. I thank you and hope such opportunities will exist for future students.

12. The global change fellowship was vital to my progress in the doctoral program at the Yale School of Forestry and Environmental Studies. Coursework I did at Yale has proved more key for my career than I ever expected, particularly in the arena of forest policy and the policy sciences. Milton Constantin and Mary Kinney deserve much credit for running a tight ship all these years. Thanks ORISE, Milton, and Mary.

13. Thank you very much for the wonderful support I received as a GREF graduate fellow! I really appreciated everything, and I miss seeing all the wonderful folks I met. As far as my career goes, I am doing pretty well. I definitely don't think I would have this job if I hadn't been in the GREF program.

\section{I think the fellowship program was wonderful.}

15. The Global Change Fellowship provided me with the opportunity to explore how scientific data is compiled, analyzed and prepared for Congress on important air quality issues. The work I conducted at The National Academies of Science gave me a great foundation for pursuing my present career as an air quality consultant in which I am responsible for understanding and interpreting air quality regulations for industrial clients.

16. The research that I conducted thru the fellowship program is currently in press in the journal Soil Biology \& Biochemistry (2 manuscripts). My current position at Rice University is a non-paid Visiting Postdoctoral Research Associate position. However, I am currently interviewing at Southern Illinois University for a postdoctoral fellowship working on research similar to my dissertation research. The professor I am interested in working with at SIU is also working in collaboration with Dr. Julie Jastrow at Argonne National Lab. Dr. Jastrow happens to have been my fellowship program mentor. She has made me aware of job opportunities and has been a great support to me. The fellowship program has been and continues to be instrumental to my career development.

17. I thought Jeff, Milt and Mary were fantastic. They were very supportive and encouraged all of us. This is a GREAT fellowship. I learned so much from my DOE/LLNL mentors and collaborators--thank you to them for putting in so much time and energy.

18. I greatly appreciated the support I received through the global change fellowship. It provided me with a degree of flexibility in graduate research that allowed me to be creative in ways that would not have been possible had I been more tied to funding through a particular grant.

19. I think the GFGC was pivotal for my career. It afforded me the opportunity to branch out from the research my advisor proposed (to NSF) and focus on the climate change research that I was most interested in. The practicum at Brookhaven taught me sampling and analytical protocols using an instrument system which I have subsequently acquired for my own laboratory (from an NSF grant) and use for just about every research project I have been involved with. The paper that resulted from the practicum research is my most cited paper and the one that has provided me with the most name recognition. The GFGC meetings also provided good contacts between myself and other GFGC fellows, including the insight gained during those interactions about other research areas. 
I don't know if it helped with getting my research funded by DOE or not, but it sure didn't hurt. I think this program was definitely one of the best graduate fellowship programs around during the 1990's and I hope that it can grow strong again.

20. The fellowship was a fabulous experience and a critical foundation for my career. Simply put, I would not have been able to achieve the same level of scientific and professional success without GCEP.

21. I am Staff Scientist for the Senate Homeland Security and Governmental Affairs Committee and principal energy and environmental advisor for United States Senator Susan Collins. My job activities include writing legislation on climate change and helping to craft a national energy policy.

22. I completed a postdoc at the University of California Santa Barbara after completing my doctorate. Between the postdoc and my current position (assistant professor in the Marine Science Program) I spent 2 years at the College of Charleston as a visiting assistant professor teaching oceanography.

23. Though the job I will soon be undertaking is focused on climate change policy in California, I do plan publish articles from my dissertation and further develop my expertise in deforestation, land use, and climate change (the topic of the research funded by GCEP) in the future.

24. The DOE fellowship program was instrumental in the completion of my Ph.D. and the development of my research program and interests. I have continued in academia and the research I started while in graduate school has continued to evolve. I very much appreciate the support I received in this program.

25. In my current position, I help determine the priorities on which Audubon focuses its conservation efforts, including identifying priority species, habitats, sites, and significant threats. My experience with global change research has been important in helping to evaluate the implications of climate change for priority bird species and habitats.

26. My scientific training has aided in Vegan Outreach's rigor: http://www.veganoutreach.org/advocacy/goodinfo.html.

27. My GCEF fellowship was critical to my development as a scientist and allowed me to pursue my doctoral work without worrying about my personal funding. It also introduced me to the national lab system--which is where I am currently working--and enjoying it very much!

28. My current research is directed at understanding the factors involved in undergraduate student learning of biological concepts and the assessment of learning/teaching. I am currently seeking collaborations within MSU that would reconnect me with my former biological science interests.

29. Being awarded the DOE Graduate Fellowship was an absolutely critical turning point for me. It enabled my graduate studies, which in turn have allowed me to have an initial successful trajectory in my career. Thanks very much for the support.

30. The fellowship was critical to my successful completion of my doctoral program. This enabled me to gain a position leading a small team of scientists working in the non-profit sector. Over time I became the Chief Scientist of an international non-profit organization. I now am no longer in research as I am the CEO of a well-respected institution.

31. Although I am currently working in the private sector, ORISE support was totally critical to my supporting graduate studies, and because of this support I gained the expertise and experience that I now rely on heavily. Keep up the good work.

32. I really appreciated the personal side of GCEP. The program directors and managers have been very supportive and encouraging. My friends who have other graduate fellowships envy the personal contact that the GCEP students have with each other and those running the program. I also think that having SURE and GREF students interact is a very positive experience for both groups. Great program! I have encouraged many to apply. 
33. Though I am not directly involved in research, the research and conceptual approach to ecosystem classification that I completed under my DOE fellowship has strongly influenced my career as a conservation scientist and planner.

34. I am doing industrial research and development with General Motors Corporation. The area of my research is in Revenue Management. Prior to joining GM in 2002, I did industrial research and development in the area of automated and optimized Strategic Sourcing (Procurement \& Purchasing) with Emptoris, and prior to this did work in the area of Aircraft Fleet Assignment, Routing, Hotel Revenue Management, and Truck Routing with Sabre and ILOG. All of my research and development work is built on the foundation of optimization.

35. The DOE GCEP GREF Fellowship was an incredible opportunity, both to pursue my dissertation research into the effects of global change on terrestrial ecosystem functioning, and to network with peers as well as senior scientists in my field. Thank you for all of your hard work with this program.

36. The fellowship program gave me a start on my graduate career in atmospheric sciences. It allowed me to eventually complete my Ph.D. and gain employment at a NASA contractor as a Research Scientist.

37. The Global Change program was excellent and really helped contribute to my academic success.

38. The GCEP graduate program was vital to my success. The support it gave me allowed me to think somewhat outside the box and explore my research ideas; ideas that are on the edge of mainstream. I feel confident that these new directions that my research is headed in will help give me an edge in new branches of dendroecology. I am very grateful for the existence of the GCEP program and the folks who care for/run/fund it.

39. Although I am not currently working in the science field, the skills that I developed as a doctoral student and as a recipient of a government fellowship are indispensable in my work as a nonpartisan researcher in state government. Because I was limited geographically to the Twin Cities after my doctoral work for personal reasons, I was resigned to look for a position outside of my immediate field of study. I found that my association with the DOE and ORISE, in addition to my research skills, afforded me the leverage to qualify for a position that I did not otherwise have any direct experience. And, I thank GCEP for that opportunity. Please let me know if there is anything I can do to help GCEP in advancing their mission and growing attendance in the program.

40. The fellowship program allowed me to solidify my interest in the investigation of our environment and global change. I would strongly endorse the program and hope that future students could benefit from it the way I have.

41. The fellowship program was an integral part of my graduate education and has contributed to my scientific and professional development.

42. The Global Change Fellowship program was immensely helpful in getting my career off to a strong start. I really valued the support and connections of the program. As a faculty member at MSU, I remain active in global change work, focused on landscape dynamics issues, and have been successful in funding my work through grants from several Federal and State agencies. Thank you again for your commitment to supporting young scientists!

43. From January 1998 to June 2005, I worked for the U.S. Geological Survey at the Patuxent Wildlife Research Center in Laurel, Maryland as a wildlife biologist specializing in amphibian population monitoring. From 20012005, I was the Amphibian Research and Monitoring Initiative (ARMI) Northeast Coordinator. My husband and I have a son, so I am currently focusing on being a full-time mom.

44. The GCEP GREF program was a fantastic experience. The fellowship not only supported my research, but also gave me the ability to establish a more independent path in graduate school. In addition, since graduating, I have come across many of the other fellows whom I had met at the annual summer workshops; and it has been really beneficial to have contact with other early career scientists.

45. My fellowship provided support for my graduate program - which resulted in my current faculty position. Some of my current research relates directly to my fellowship research on hurricane impacts. My fellowship also provided me multiple opportunities for networking with other scientists. These opportunities lead to collaboration on projects and manuscripts that significantly helped my career. 
46. I am currently conducting research forecasting effects of climate change on animal populations, among other projects. My fellowship with DOE was an important step in obtaining my current position, and in obtaining funding for the climate change research.

47. The DOE fellowship was instrumental in my being able to complete a Ph.D., AND it allowed me to pursue research in global climate change and forest dynamics in the Sierra Nevada forests, which led to my current job (and tenure!) at CSU Fresno, the closest university to Yosemite, Sequoia \& Kings Canyon National Parks and all of the nearby National Forests. The synergy of the research background, contacts \& potential research collaborators, and university position allowed me to compete successfully for ample grant monies to keep my lab running with 3-4 graduate students at a time. I strongly encourage any future efforts to provide fellowship opportunities to additional graduate students and post-docs. My sincere thanks, also, to Milton and Mary for keeping everything running so smoothly.

48. The DOE Fellowship program allowed me to experience more of the interworkings of National Labs and National Agencies, and to meet more colleagues, than I might have had I not been involved. Since graduating, I have continued in the same field of climate research that I studied in graduate school. I am now a climate research scientist working for the University of Colorado, working in a lab that consults with NOAA on a globalscale project. It is very exciting work, and the various experiences in the fellowship program definitely helped motivate me to stay within this field of research.

49. I am very happy to have had the experience of the DOE fellowship. The fellowship added to my career greatly by opening up new opportunities and fundamentally supporting the completion of my PhD. Following my PhD at Penn State University (completely Dec 2002), I worked as a research scientist for GNS Science in New Zealand (July 2002-2006). I have just recently moved back to the U.S. after accepting a permanent position with the USGS Cascade Volcano Observatory. My research here involves work that is very closely related to my research conducted under the DOE Fellowship. Thank you very much!

50. The summer internship part of the fellowship program was a great opportunity to work at a government laboratory and make new professional contacts.

51. The fellowship opportunity was a fantastic opportunity for me to finance my graduate education and pursue the kind of graduate research I wanted. The Research Collaboration experience at Oak Ridge National Laboratories with Wilfred M. Post was also very gratifying. I finished my time at Penn State with an M.S. in Geography. After a year, I found work with a government defense contractor ( $\mathrm{CACl}$, Inc.) in the Washington, DC area doing software development using GIS (geographic information systems). So I did not continue doing research however I did use skills from my degree including computer and software development skills I used doing the collaborative research with the fellowship.

My software development at the company turned more to financial applications after several years at the company. After seven years with the company, I decided to take a break to travel for one year. I have been using my computer skills and knowledge about geography, the earth sciences, and global change, to write about my experiences on a website, http://www.itinerantwitness.com. When I return, I may continue in my software development career or turn to something that uses more of my knowledge in geography and the earth sciences.

The fellowship was a fantastic opportunity for me. I enjoyed the fellows' conference in Oak Ridge where we shared our experiences. I did struggle at the time to find a place and person with whom to do my collaborative research experience, because my research advisor at Penn State did not have any connections with the DOE researchers. (I applied for and won the fellowship before I arrived at Penn State.) So I recommend that anything you can do to make it easy for fellows to contact DOE researchers would be extremely helpful. This might include making DOE researchers aware of the program and its purposes. In addition, coordinating with the DOE facility (in my case Oak Ridge) about logistics to make it easy for a fellow to move for a three-month period would be helpful. In the end, I found a good project on which to work. Other than that, I had a good experience as a DOE Global Change Fellow, and I thank DOE, the Global Change Fellow program, and Milton Constantin for the opportunity.

52. I believe that my fellowship program was very helpful to me by offering me experiences and opportunities that I otherwise would not have had. After moving from university research to a private environmental restoration company several years ago, I simultaneously became disillusioned with the company and had an opportunity to switch careers to independent computer consulting. While I am not directly doing science anymore, I do work with 
researchers at the local NIH lab on a regular basis, but in a support role, not as a researcher myself. However, I would not have the opportunity to do this work if it were not for my science-based graduate degrees. I am supportive of the ORISE program and am grateful that it was available to me during my graduate years.

53. I feel very fortunate to have had the fellowship, and the associated opportunity to create my own research area and pursue my own research directions.

54. The DOE Global Change fellowship program was integral in allowing me to finish my degree. My doctoral work has continued to influence my teaching and scholarship. Receiving federal funding for my doctorate has increased my commitment to public service as well, and I devote a considerable amount of time to service activities in the communities and local schools. 